\title{
Röntgenvorlesung mit Sascha Lobo
}

Können und wollen wir Maschinen unsere Gesundheit anvertrauen? Der Autor und Blogger Sascha Lobo wird in der diesjährigen Röntgenvorlesung darüber sprechen, warum der digitale Wandel alternativlos ist und weshalb er Radiologinnen und Radiologen in einer Avantgarde-Funktion innerhalb des Gesundheitssystems sieht.

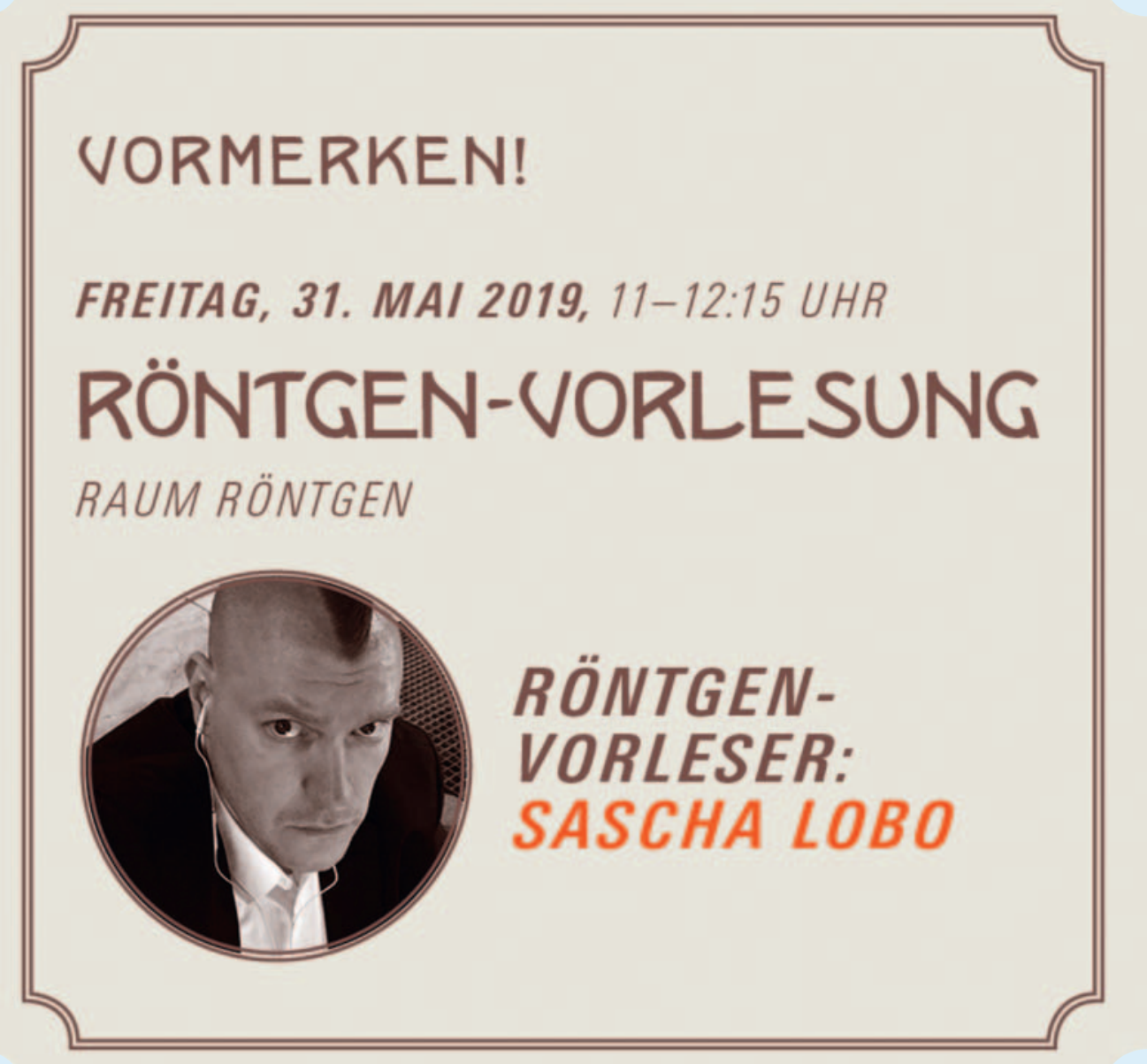

„Das klassische Problem ist, dass das Gesundheitssystem in Deutschland seit vielen Jahrzehnten auf einem extrem hohen Niveau unterwegs ist, was mit einer bestimmten Form von Fortschritt konfligiert. “

„Die Disruption des Gesundheitssystems kommt auf uns zu, und Radiologinnen und Radiologen stehen an der Spitze derjenigen, die davon zuerst betroffen sein werden."

„Es gibt ein Urvertrauen in bestimmte Maschinenprozesse, das selten hinterfragt wird.“

„Das größte deutsche Vermögen ist zweifellos das Beharrungsvermögen, und das macht sich im Gesundheitssystem besonders bemerkbar.“

Lesen Sie das vollständige Interview mit Sascha Lobo in Leipzig im offiziellen RöKo-Magazin der Deutschen Röntgengesellschaft. 